\title{
Resenha
}

\section{“Geografia Física Crítica": Uma iniciativa louvável, mas de concretização enviesada}

\author{
Marcelo Lopes de Souza
}

The Palgrave Handbook of Critical Physical Geography, Rebecca Lave et al. (orgs.). Londres, Palgrave, 2019, 628 pp., ISBN 978-3-319-71461-5.

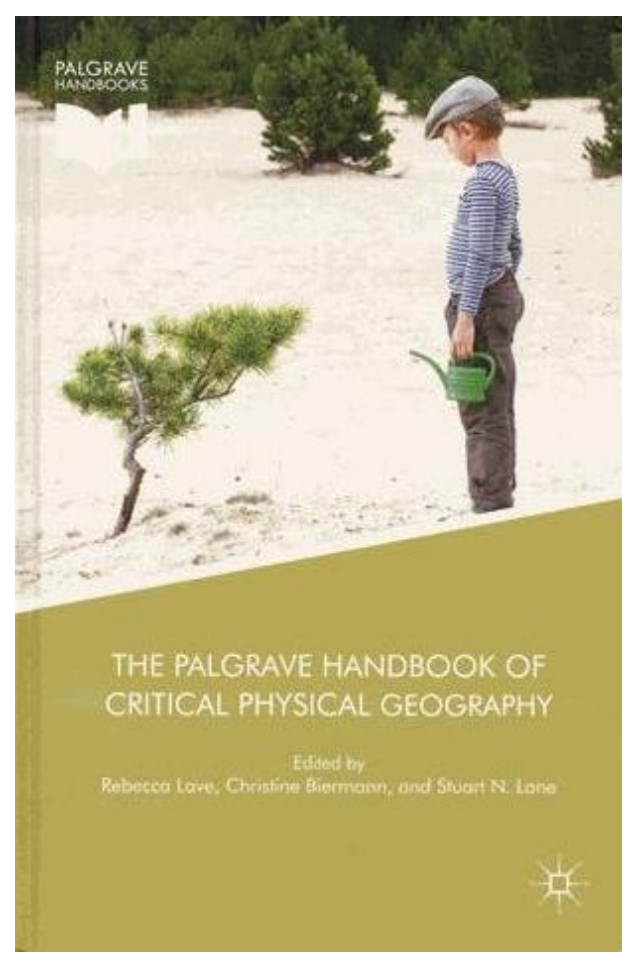

Já vinha sendo gestada há um certo tempo uma empreitada que agora, com a publicação em 2019 do alentado (628 páginas) The Palgrave Handbook of Critical Physical Geography, se concretiza em uma 
obra que, tanto por seu ambicioso escopo quanto por sua elevada qualidade, tem tudo para se converter em símbolo e marco de uma corrente científica. Essa empreitada se autodesigna pelo nome de "Geografia Física Crítica", expressão que vem se popularizando desde o aparecimento do seminal artigo assinado por Rebecca Lave e dezoito colaboradores intitulado "Critical Physical Geography" (LAVE et al., 2014). O que é, porém, isso? E o que essa iniciativa oferece de novo a nós, geógrafos brasileiros e latino-americanos em geral?

Em meio ao cada vez mais profundo fosso que, especialmente a partir dos anos 1970, vem colocando em campos opostos e mutuamente hostis geógrafos humanos (inebriados com as supostas vantagens de uma "ciência social pura", ou seja, desembaraçada do estorvo em que consistiriam os conhecimentos ecogeográficos) e físicos (crescentemente interessados em se afirmar enquanto geomorfólogos, climatólogos etc., em detrimento da identidade de geógrafos), ${ }^{1}$ uma acusação foi e tem sido corriqueira, da parte dos primeiros em relação aos se-

\footnotetext{
${ }^{1}$ Para não sobrecarregar esta resenha com aspas, me abstenho de aspear, no corpo do texto, as expressões "geógrafos humanos" e "geógrafos físicos", e o mesmo farei com relação a "Geografia Humana" e "Geografia Física". No entanto, como já tive oportunidade de discutir em outras ocasiões, essas expressões me parecem bastante problemáticas: "Geografia Humana" (e o seu derivado "geógrafos humanos"), ao ressaltar como central uma característica biológica, isto é, o pertencimento à espécie humana, quando, na realidade, o adjetivo social seria bem mais
}

gundos: aquela de que os geógrafos físicos, além de incorrigivelmente positivistas, seriam, ainda por cima, por conta de seus preconceitos cientificistas (a começar pela neutralidade axiológica), presas fáceis de visões de mundo conservadoras. As generalizações abusivas que, em nome desse tipo de objeção, foram cometidas contra colegas e toda uma fatia da tradição geográfica, foram muitas e frequentes. Daí surgiram mágoas e rancores, e por duas razões: para uma parcela dos geógrafos físicos, esse tipo de condenação era, pelo menos em larga medida, injusto, particularmente no que diz respeito à acusação de conservadorismo ou alienação (de Jean Tricart a Aziz Nacib Ab'Saber, passando por outros tantos exemplos, fácil seria constatar o exagero e mesmo a tolice de uma tal desqualificação "no atacado"); para outra parcela, que não se importava nem um pouco em ser vista como positivista ou conservadora (antes pelo contrário), a hostilidade foi um estímulo adicional para que se apressassem em tentar consumar a sua independência em face da Geografia (algo muito

adequado; quanto à "Geografia Física" e aos "geógrafos físicos", o adjetivo "físico" soa, aos ouvidos do século XXI (ou já do século XX, crescentemente, desde que a ciência denominada Física, de escopo bastante restrito, se consolidou e popularizou), um tanto pobre e reducionista, sendo o qualificativo ecológico mais apropriado. Por isso, já há muitos anos, optei por empregar as expressões alternativas Geografia Social (pioneiramente utilizada por E. Reclus) e Ecogeografia (que tomo de empréstimo a Jean Tricart). 
difícil de se alcançar plenamente, dada a inexistência de cursos de graduação para a formação de geomorfólogos, entre outros fatores).

Em face dessa tensão intradisciplinar, com a qual convivemos, em sua forma atual, já há quase meio século, eis que surge, a partir da Geografia anglo-saxônica, uma corrente que ostenta o nome de "Geografia Física Crítica", e cujos lemas deveriam soar como música para os ouvidos de muitos geógrafos humanos: recusar o positivismo; compreender os processos geoecológicos como histórica e culturalmente situados (e, nesse sentido, inerentemente sociais); adotar uma perspectiva de crítica social e inconformismo perante o mundo, o que faz com que a análise da realidade geobiofísica seja inseparável da consideração de relações de poder. Seria isso uma admissão, ainda que tardia, de que a Geografia Humana crítica ou radical que emergiu nos anos 1970 e 1980 tinha, afinal de contas, razão? De certo modo, sim. Porém, as coisas quase nunca são tão simples quanto parecem à primeira vista, não é mesmo?

De seus 26 capítulos, organizados em torno de três densas partes, os mais importantes e representativos,

\footnotetext{
${ }^{2}$ Muito embora haja bastante subjetividade em uma tal seleção, eu destacaria, por sua originalidade e outras qualidades, sobretudo os seguintes capítulos (sem demérito para os demais): "In Defense of Crappy Landscapes" (Cap. 3), "The Trouble with Savanna and Other Environmental Categories, Especially in Africa" (Cap. 6), "How the West Was Spun: The De-politicization of Fire in the American West" (Cap. 8), "Critical Invasion Science: Weeds,
}

para efeito de conhecimento da natureza e das propostas da Critical Physical Geography, são os dois primeiros - "Introducing Critical Physical Geography" (assinado pelos três organizadores da coletânea, Rebecca Lave, Christine Biermann e Stuart N. Lane) e "Towards a Genealogy of Critical Physical Geography" (igualmente assinado por eles, mas em uma ordem distinta, com Stuart N. Lane como primeiro autor) - e o último "Critical Reflection on a Field in the Making" (também de autoria dos três organizadores, que, como se vê, regem com zelo a orquestra; no caso desse capítulo, Christine Biermann é a primeira autora). Quase todos os demais capítulos, envolvendo seis dezenas de autores, são, independentemente de seus méritos e de sua relevância, essencialmente ilustrações (muitas ótimas, e algumas delas excelentes e brilhantes ${ }^{2}$ ) das potencialidades da "Geografia Física Crítica". Nos parágrafos a seguir, que têm menos a intenção de radiografar a obra que de interrogá-la criticamente e com ela dialogar, o foco serão, basicamente, as afirmações e interpretações centrais contidas naqueles três capítulos mais diretamente programáticos, os quais

\footnotetext{
Pests, and Aliens" (Cap. 12), "Beyond 'the Mosquito People': The Challenges of Engaging Community for Environmental Justice in Infested Urban Spaces" (Cap. 14), "Race, Nature, Nation, and Property in the Origins of Range Science" (Cap. 16), "Soils in Ecosocial Context: Soil pH and Social Relations of Power in a Northern Drava Floodplain Agricultural Area" (Cap. 19) e "The Science and Politics of Water Quality" (Cap. 22).
} 
podemos chamar de "vertebradores".

Antes de prosseguirmos, seja permitida uma nota pessoal, a título de explicação e contextualização da minha abordagem e das minhas intenções. $O$ autor destas linhas tem se dedicado, desde os tempos de estudante de graduação, aos assim chamados "estudos urbanos"; ele tem sido visto, por consequência, como alguém vinculado à Geografia Humana. Apesar disso, e sem querer repudiar essa classificação (muito embora eu recuse, como registrei já na nota de rodapé $\mathrm{n}^{0} 1$, o rótulo "Geografia Humana", preferindo a expressão reclusiana Geografia Social), nunca houve, da minha parte, uma adesão ao modismo de rechaçar e desdenhar a Geografia Física. A amizade e a influência duradoura de Orlando Valverde 3 (que tive a ventura de conhecer pessoalmente antes mesmo de entrar para o curso de graduação), somadas a um doutoramento na Alemanha (ambiente intelectual que mais resistiu à fragmentação da Geografia e às tendências "purificadoras" das décadas de 1970 e 1980), foram vacinas suficientemente fortes para me imunizar contra uma postura de aversão aos conhecimentos e con-

\footnotetext{
3 Orlando Valverde (1917-2006), conhecido, em primeiro lugar, como o principal expoente da Geografia Agrária no Brasil durante décadas, além de ser o pioneiro, entre nós, de uma Geografia Agrária de cunho crítico (seu envolvimento com o tema da reforma agrária remonta aos anos 1950), foi, ao mesmo tempo, um precursor da Ecologia Política na Geogra-
}

tribuições dos geógrafos físicos. Digo isso porque, como se verá, minhas ressalvas não são as de um opositor da Geografia Física - na verdade, são ressalvas que, isso sim, partem de um aliado, ou de alguém que se entende como um companheiro de viagem, e cujo intuito é o de colaborar para que alguns equívocos sejam percebidos e corrigidos.

Já expus, no terceiro parágrafo, a quintessência do conteúdo explícito da "Geografia Física Crítica" (doravante, por comodidade, referida como GFC): recusa do positivismo, rejeição das visões de mundo acríticas e conservadoras e denúncia da impropriedade da crença em uma ciência neutra em relação a valores. $O$ que interessa, agora, é sobretudo examinar e problematizar certas premissas epistemológicas e teórico-metodológicas, assim como um determinado substrato cultural, do qual parecem emanar alguns pressupostos (em geral tácitos e com certeza nem sempre conscientes) que, para um geógrafo brasileiro e latino-americano, deveriam levar a franzir o cenho - e, por mais que alguns problemas já não sejam surpresa, também a levantar as sobrancelhas. Do meu ponto de vista, são três os problemas principais:

fia brasileira. Ademais, mesmo sem fazer pesquisas originais nesse campo, sua familiaridade com a Geografia Física era gigantesca (característica típica do figurino da Geografia Humana clássica), tendo ele, inclusive, entre outras coisas, atuado como tradutor de um livro de Pedologia. 
1) A "Geografia Física Crítica" se apresenta, na prática, como um sucedâneo da Ecologia Política, cujas lacunas ela critica - ainda que, ao que parece por mera diplomacia, os organizadores afirmem, muito de passagem, que a GFC pretende ser complementar à Ecologia Política, e não uma alternativa a ela ("Introducing Critical Physical Geography”, pág. 14), observação que soa contraditória em vista de todo o restante. O que é cobrado da Ecologia Política é, em grande medida, correto, mas já vem sendo admitido por geógrafos a ela dedicados, como Peter Walker (WALKER, 2005) e eu mesmo (SOUZA, 2019a, pp. 100, 303-304): a Ecologia Política vem, já há bastante tempo, negligenciando os conhecimentos ecológicos ou geobiofísicos, o que tem levado, em não poucos casos, a um discurso sobre a "natureza" ou o "(meio) ambiente" que não está solidamente alicerçado em conhecimentos a propósito dos processos geoecológicos concretos. Ocorre, todavia, que a cobrança dos proponentes da GFC não para aí: exige-se que a Ecologia Política seja responsável por pesquisas originais e geração de dados geobiofísicos (cf. Cap. 2, "Towards a Genealogy of Critical Physical Geography", pág. 25), o que corresponde a desconhecer e deturpar a

\footnotetext{
${ }^{4}$ Tanto é que, dos dezoito capítulos que abordam casos ou problemas concretos, baseados em pesquisas empíricas, na esmagadora maioria deles se percebe que os métodos e técnicas de pesquisa das ciências da sociedade não tiveram, de forma alguma, o mesmo peso
}

proposta daquele campo. Além do mais, ao apresentar o que seriam as suas características distintivas, a GFC erra o alvo ao pretender ser "mais integradora" que a Ecologia Política, na medida em que apenas ela articularia de forma densa, completa e equilibrada os conhecimentos das duas Geografias, física e humana ("Introducing Critical Physical Geography", págs. 3-4 e 9-12). Pois bem: isso é de uma megalomania assustadora. Apesar do nome "Geografia Física Crítica", os organizadores da coletânea não hesitam em dar a entender, principalmente nos dois capítulos iniciais, "Introducing Critical Physical Geography" e "Towards a Genealogy of Critical Physical Geography", que os adeptos da GFC são ou deveriam ser capazes de manejar todo o arsenal teórico-conceitual e metodológico da Geografia, inclusive os métodos e as técnicas da pesquisa mais especificamente social! Perguntamos: quantos gênios renascentistas polímatas, no estilo de um Leonardo da Vinci, esperam eles que apareçam e se sintam à vontade para demonstrar proficiência em todo o largo espectro de métodos e técnicas à disposição da pesquisa geográfica? Não é provável que muitos daqueles que se identificam com a GFC endossem plenamente essa pretensão, ${ }^{4}$ mas é isso

que os métodos e técnicas das ciências da natureza. Por mais que a maior parte dos trabalhos demonstre alguma familiaridade com teorias, conceitos e até mesmo métodos típicos da pesquisa social, o enfoque adotado é, cristalinamente e acima de tudo, ecogeo- 
que, ao fim e ao cabo, dá o tom dos capítulos mais programáticos da obra, sendo mostrado como a face epistemológica dessa corrente. ${ }^{5}$

Ora, a Ecologia Política, sem dúvida alguma, não deveria nunca subestimar e deixar de lado os conhecimentos da pesquisa natural. Se antropólogos e outros profissionais que colaboram com esse campo interdisciplinar assim procederem, isso é talvez um pouco desculpável, mas nem por isso devemos, os geógrafos, querer imitálos! No entanto, a Ecologia Política surge, historicamente, a partir das ciências da sociedade, e não há nada de intrinsecamente ruim em que, no caso dos geógrafos, o olhar basicamente sociogeográfico se faça presente de maneira mais acentuada. Na verdade, os geógrafos que se dedicam à Ecologia Política deveriam ser, para os adeptos da GFC, parceiros - e vice-

gráfico. As três únicas exceções são os capítulos "How the West Was Spun: The De-politicization of Fire in the American West", de autoria de Gregory Simon - não por acaso, um pesquisador que vem da tradição da Ecologia Política -; "Beyond 'the Mosquito People': The Challenges of Engaging Community for Environmental Justice in Infested Urban Spaces", de Dawn Biehler et al.; e "Coffee, Commerce, and Colombian National Soil Science (1929-1946)", de Greta Marchesi, que é, no fundo, um trabalho de Geografia Agrária (e com um nítido perfil de Ecologia Política).

${ }^{5}$ No capítulo de conclusão, os três organizadores, sensatamente, concedem que "[...] encontrar revisores aptos pode se mostrar extraordinariamente difícil no que concerne a uma parcela da GFC [for some CPG scholarship]", acrescentando, logo em seguida, que "[p]ara estudantes que almejarem realizar esse tipo de trabalho integrativo, é desafiador encontrar orientadores e mentores que sejam capazes e tenham von- versa. Estes últimos podem ter preocupações muito semelhantes às dos primeiros; contudo, se pretenderem ser "geógrafos totais", em vez de serem, essencialmente e em primeiro lugar, geógrafos físicos (ou, como prefiro, ecogeógrafos), como que querendo quase se confundir com a Geografia em sua totalidade, estabelecerão uma meta irrealista. Mais do que isso, estarão, ao mesmo tempo, injustamente, diminuindo a importância da Ecologia Política.

2) Fazendo um pouco, agora, o papel de um "advogado do diabo", seria lícito provocar: será que ao objetivar, com uma ambição desmedida, dominar também as teorias, os conceitos e os métodos da pesquisa social, os adeptos da GFC não estarão correndo o risco de sucumbir a uma perda de identidade? Uma coisa é melhor informar-se, conversar e levar a sério deter-

tade de orientar tais projetos" (pág. 570). Seja lá como for, esse lampejo de realismo, além de insuficiente, empalidece diante da tendência de superestimação das próprias possibilidades que nitidamente predomina nos capítulos de abertura da coletânea. Dos autores da coletânea, é Salvatore Engel-Di Mauro, autor do capítulo "Soils in Ecosocial Context: Soil PH and Social relations of Power in a Northern Drava Floodplain Agricultural Area", quem oferece a interpretação mais equilibrada e justa das possibilidades e tarefas da GFC: "Unlike much earlier attempts at combining ecology (or biology) with social theory, such as ecofeminism, political ecology, and eco-Marxism, CPG is based on studying and explaining biophysical phenomena while accounting for (not explaining, it should be underlined) the social contexts wherein human impacts as well as scientists are embedded [...]. Thus, CPG not only helps reveal explanatory processes unaccounted for in societyfocused theories but also helps unite what remains fragmented within geography." (pp. 394-395) 
minadas críticas e ponderações dos geógrafos humanos, dentro de um espírito de intercâmbio; coisa muito diferente, no entanto, é querer emular as práticas profissionais dos colegas que passam uma vida inteira mergulhados em teorias e conceitos de ordem econômica, política e cultural e treinando métodos e técnicas como surveys, análise crítica de discurso e etnografia. Abraçar o diálogo, com modéstia e superando os ressentimentos, é algo muito válido; diversamente, a emulação de posturas profissionais é, com certeza, um empreendimento frágil - e, acima de tudo, desnecessário. Curiosamente, é como se muitos adeptos da GFC tivessem introjetado a tal ponto um certo complexo de inferioridade que, para eles, já não basta conhecer e cooperar; é preciso buscar ser o Outro, adotando uma estratégia de mimetismo. Irônica e lamentavelmente, a maioria dos geógrafos humanos, com exceção daqueles que têm se dedicado à "Geografia Ambiental" que vem emergindo nos últimos $\operatorname{anos}^{6}$ (e, claro, com exceção também dos que sempre contribuíram explicitamente com a Ecologia Política), não parece muito inclinada a aceitar a mão estendida pela GFC, e muito menos a fazer um esforço equivalente (isto é, passando a se informar melhor e interessar mais pelos processos geoecológicos e sobre como eles influenciam os processos de produção social do espaço). Com isso, estamos diante de uma assimetria: a GFC parece, para além de suas inegáveis virtudes, e ao se apresentar como uma espécie de "Geografia integrada total", ser resultado de uma insidiosa colonização da Geografia Física (melhor dizendo, daquela parcela que ainda se interessa genuinamente pela Geografia...) pela Geografia Humana (Crítica). Para a GFC, isso não é muito meritório, e pode ser, isso sim, uma grande armadilha, pois talvez o exagero dificulte, em vez de facilitar, que ela consiga trazer de modo convincente e robusto o aporte que lhe é próprio (e que é insubstituível). Interessantemente, para a Geografia Humana, uma tal "colonização" não passaria de uma vitória de Pirro: os geógrafos ditos humanos precisam, com urgência, valorizar os objetos de conhecimento híbridos e o diálogo com as contribuições ecogeográficas, como vem se esforçando em fazer a Geografia Ambiental; em nada lhes ajuda (mesmo que isso não seja por eles percebido) ter uma "colônia epistemológica e político-filosófica" que atende pelo nome de "Geografia Física Crítica" - por mais que a "colônia", bizarramente, pareça, em um delírio de grandeza, ter pretensões de ser uma espécie de "metrópole expansionista”, onívora e

\footnotetext{
${ }^{6}$ Sobre a Geografia Ambiental, suas raízes, seus propósitos e suas potencialidades, consulte-se, por exemplo, SOUZA (2019b).
} 
insaciável, conforme mencionado no parágrafo anterior.

3) Já que falamos em "colônia" e "metrópole", chego à crítica mais ancorada em minha própria situacionalidade de pesquisador brasileiro: a GFC é inacreditavelmente (bem, "inacreditável" não seria o termo mais exato...) ensimesmada, sob os ângulos acadêmico e cultural. Fomos tendo de aceitar, ao longo das décadas, que geógrafos anglófonos quase nunca tomam contato com as Geografias produzidas em outros idiomas; a dominância da língua inglesa, fenômeno que se impõe pela astronômica quantidade de produção acadêmica e, em boa medida, também pela qualidade (que, entretanto, é costumeiramente superestimada), é de tal monta que, de um modo geral, há como que um pressuposto tácito de que aquilo que não está em inglês, não é digno de nota. Ou, para dizer de modo mais brutal: aquilo que não está em inglês, é como se não existisse. É óbvio que, perante os ambientes intelectuais francês e alemão (tratados mais ou menos como "mestres do passado" ou "veneráveis nichos de uma alta cultura um pouco decadente"), há, não raro, um misto de condescendência e admiração, o que faz com que uns tantos pensadores e pesquisadores da Europa Continental sejam traduzidos e até incensados em alguns círculos anglo-americanos (bastam os exemplos de Henri Lefebvre, Michel Foucault, Bruno Latour e da Escola de Frank- furt). Já os latino-americanos não são, evidentemente, encarados da mesma maneira, e aí vemos como as barreiras linguísticas são potencializadas pelos preconceitos etnocêntricos. Quando examinamos The Palgrave Handbook of Critical Physical Geography, é flagrante a escassez de qualquer coisa que não seja a própria produção anglo-saxônica - e isso não parece incomodar nem um pouco os autores da obra, a começar pelos três organizadores. Dos 61 autores que participam da coletânea, somente onze não estão baseados em um país anglófono; e mesmo assim, quase todos esses onze tiveram ou têm laços muito estreitos de trabalho e cooperação com o mundo acadêmico de língua inglesa. Com a exceção de Monica Castro, jovem pesquisadora formada em Biologia na Colômbia e com um doutorado em Geografia na França (onde ela trabalha), terceira em um artigo que conta com seis autores ("Mapping Ecosystem Services: From Biophysical Processes to (Mis)Uses"), não há um único pesquisador latino-americano. Como se isso não bastasse, e como uma decorrência sintomática, quase não são citados, ao longo das mais de seiscentas páginas da obra, trabalhos que não tenham sido publicados em inglês e sejam fruto do ambiente científico anglo-saxônico. Há uns poucos em francês e um ou outro em alemão, que, em grande parte, são livros clássicos ou antigas obras de referência. Não há, entre os trabalhos citados, um 
único sequer em espanhol ou português: a produção latino-americana, vasta e rica, é tornada, assim, invisível.

Fica patente que a GFC proposta pelos colegas de língua inglesa dialoga com o espelho, narcisisticamente. Não deixa de ser espantoso, conquanto talvez previsível, que a obra passe a impressão de que um olhar socialmente crítico, politizado e não positivista dentro da Geografia Física se tenha tornado substancial apenas com o aparecimento da GFC; concedese, aqui e ali, que houve precursores ou algo do gênero, mas mesmo estes são buscados e encontrados apenas dentro das fronteiras do mundo acadêmico anglo-americano. ${ }^{7}$ Um geomorfólogo e pensador da Geografia como Jean Tricart (para ficar em apenas um exemplo), que já nos anos 1950 estabelecera uma distinção entre

\footnotetext{
7 Quando, no capítulo de conclusão ("Critical Reflection on a Field in the Making"), os organizadores do livro admitem que "[...] a GFC não é única em sua procura pela interdisciplinaridade [...]" (pág. 559), igualmente reconhecendo que "[h]á numerosos exemplos de pesquisas integrativas inovadoras anteriores à GFC e que vão bem além da Geografia" (pág. 561), essa porção de humildade não chega a compensar ou neutralizar a pretensiosidade presente nos dois capítulos de abertura, nos quais há um cristalino exagero ao se discorrer sobre as vantagens e particularidades da GFC (mormente, como já se viu, na comparação com a Ecologia Política). O capítulo conclusivo, mais lúcido e melhor balanceado que os dois iniciais da obra (o que talvez tenha a ver com o fato de que, apesar de os autores serem os mesmos, a ordem não é a mesma, o que sugere que a responsabilidade autoral não foi exatamente simétrica), acerta ao qualificar algumas das especificidades da GFC, mas falha ao omitir por completo, entre os desafios do campo, a ultrapassagem (ou, pelo menos, mitigação) do etnocentrismo.
}

uma "Geomorfologia marxista" e uma "Geomorfologia burguesa" (TRICART, 1953 e 1956), é solenemente ignorado. ${ }^{8}$ Note-se, aliás, que o nome de Tricart - raro caso de geógrafo francês da segunda metade do século $X X$ que teve vários artigos e livros traduzidos para o inglês, sendo grande a sua repercussão entre os especialistas - nem sequer surge em momento algum. Diante disso, é lógico que os geógrafos latino-americanos não iriam mesmo receber qualquer atenção. Não obstante, cumpre lembrar que vários deles, há décadas, não vêm esperando por "guias" anglófonos para fazerem uma autêntica Geografia Física Crítica - em muitos casos, eles é que foram os pioneiros, estimulados por seu contexto econômicopolítico-cultural. ${ }^{9}$ É temerário pinçar

\footnotetext{
${ }^{8}$ Poderíamos, aliás, recuar muito mais ainda, para incluir diversos trabalhos de dois célebres geógrafos e anarquistas, o francês Élisée Reclus (1830-1905) e o russo Piotr Kropotkin (1842-1921). La Terre, de Reclus, publicado, em dois volumes entre 1868 e 1869 (RECLUS, 1868-1869), é, a esse respeito, especialmente importante.

9 Os conhecimentos humanos, e de maneira mais forte e direta aqueles que envolvem análises do mundo social, sempre guardam estreita vinculação com as condições históricas concretas. No capítulo conclusivo da obra, C. Biermann, S. N. Lane e R. Lave corretamente salientam que as polêmicas, as disputas e os conflitos a propósito do aquecimento global e temas correlatos (como o negacionismo climático) têm conduzido vários pesquisadores da Geografia Física a terem um comportamento politicamente mais ativo e inconformista (cf. pág. 560). Isso nada tem de novo: a história da Geografia Humana (crítica) exemplifica sobejamente esse tipo de conexão, com as lutas sociais de fins dos anos 1960 e início dos anos 1970 (revoltas estudantis na Europa e nos EUA, movimentos contra a guerra do Vietnã e pelos direitos civis dos
} 
alguns poucos nomes de um continente inteiro, mas cabe mencionar, para início de conversa, entre os brasileiros, Aziz Nacib Ab'Saber (1924-2012) e Carlos Augusto de Figueiredo Monteiro (1927-...), grandes mestres, respectivamente, da Geomorfologia e da Climatologia, além de Dirce Maria Antunes Suertegaray, João Lima Sant'Anna Neto e Roberto Verdum, que ajudaram ou têm ajudado a construir a rede de pesquisadores responsável pela publicação de AMBIENTES. Além destes, e dentre muitos outros, devemos ressaltar as contribuições de colegas como Hugo Romero Aravena (Chile) e Georgina Calderón Aragón (México). O triste é que, como bem sabemos, a história é escrita pelos vencedores, o que significa que uma narrativa fundacional que oblitera por completo o lugar dos geógrafos latino-americanos tem grandes chances de ser tomada pelo seu valor de face, sem o menor questionamento. ${ }^{10}$

negros nos EUA, e assim sucessivamente) atuando como estopins e catalisadores de um processo de conscientização de toda uma geração de jovens geógrafos de língua inglesa. Na América Latina, as condições crônicas de profunda heteronomia e extrema desigualdade econômico-social, tornadas agudas em determinadas conjunturas políticas (ditaduras militares), têm fornecido um caldo de cultura fertilíssimo, responsável pela emergência, já desde muitas décadas, de geógrafos preocupados com questões político-sociais (reforma agrária, reforma urbana, movimentos sociais etc.) e que, muitas vezes, em grau variável, têm sido, eles próprios, ativistas, ou então colaborado com ativismos. E esses geógrafos, não os encontramos apenas entre aqueles dedicados à questão agrária e aos problemas regionais (como, já nos anos 1950 e 1960, Orlando Valverde e Manuel Correia de Andrade) ou à problemática urbana (como Milton Santos), mas também, para ficar em um único e ótimo
À luz de tudo o que se disse anteriormente, uma conclusão se impõe: por um lado, a GFC representada pela coletânea The Palgrave Handbook of Critical Physical Geography é algo que, em si mesmo, possui muito de válido, necessário e promissor. Em matéria de assuntos específicos, a preocupação revelada em vários capítulos com a problemática da injustiça ambiental é só um dos muitos pontos positivos que podem ser apontados; aliás, a importância social e política dos temas dos capítulos, de um modo geral, salta aos olhos. Apesar disso, por outro lado, as distorções e omissões são tamanhas que, infelizmente, faremos bem em nos acautelar perante essa iniciativa, mantendo um indispensável senso crítico.

Para o bem e para o mal, The Palgrave Handbook of Critical Physical Geography é uma ilustração emblemática da corrente científica apresentada e discutida nesta resenha. O volume

exemplo, na figura de um geógrafo físico como Aziz Ab'Saber.

10 Quando, no Cap. 16 ("Race, Nature, Nation, and Property in the Origins of Range Science"), Nathan Sayre reproduz uma emblemática fotografia de 1939, retratando um agricultor hispânico do Novo México recebendo, com uma postura humilde, uma "aula" de um especialista florestal anglo-saxão, foto essa que Ihe dá o pretexto para uma aguda reflexão sobre relações de subalternização no campo do conhecimento ambiental, a situação não deixa de ser irônica: é tentador pensar que The Palgrave Handbook of Critical Physical Geography passa uma mensagem um tanto contraditória quanto a isso, uma vez que, em última instância, é como se os pesquisadores do "Norte Global" estivessem (mais uma vez), dando uma “aula" para seus colegas do "Sul Global”, cuja história é ignorada e cuja expertise é subestimada. 
de resultados de pesquisas empíricas é muito significativo, até mesmo impressionante, o que evidencia as dimensões de um ambiente acadêmico que, beneficiando-se de ter como veículo a lingua franca da atualidade, abrange uma audiência (ou um mercado...) de amplitude global, estribado em dúzias e dúzias de periódicos de ponta (via de regra controlados por umas poucas grandes editoras) e associações profissionais, organizações científicas e instituições universitárias de primeira linha. Isso é inegável, e não há por que pretender negar. Sem embargo, tudo aquilo que as lentes epistemológicas e teóricas da Critical Physical Geography deixam de lado, ou simplesmente impedem de enxergar, também é uma enormidade. Cabe a nós, latino-americanos, e igualmente a geógrafos (físicos ou não) de outras paragens (da África, da Ásia e da própria Europa), chamar a atenção, construtivamente, mas com firmeza, sobretudo para o sabor indiscutivelmente colonial e eurocêntrico (ou, meIhor ainda, anglo-americanocêntrico) que a Critical Physical Geography apresenta. Esse sabor, que seria lamentável e reprovável em qualquer circunstância, é ainda mais lamentável e reprovável em uma vertente que declaradamente se pretende crítica. Convenhamos que o mínimo que se pode esperar de um empreendimento desses é que consiga se livrar das contradições mais óbvias.

\section{Referências}

LAVE, Rebecca et al. Critical Physical Geography. The Canadian Geographer/Le Géographe canadien, v. 58, $\mathrm{n}^{\circ}$ 1, pp. 1-10, 2014.

SOUZA, Marcelo Lopes de. Ambientes e territórios: Uma introdução à Ecologia Política. Rio de Janeiro: Bertrand Brasil, 2019a.

SOUZA, Marcelo Lopes de. O que é a Geografia Ambiental?. AMBIENTES: Revista de Geografia e Ecologia Política, v. 1, $\mathrm{n}^{\circ}$ 1, pp. 14-37, 2019b.

RECLUS, Élisée. La Terre: Description des phénomènes de la vie du globe. Paris: Hachette, 2 vols. Reprodução fac-similar disponibilizada na Internet pela Librairie Nationale Française (http://gallica.bnf.fr; o endereço específico varia de acordo com o tomo), 1868-1969. 
TRICART, Jean. Premier essai sur la géomorfologie et la pensé marxiste. La Pensée, $n^{\circ} 47$, pp. 67-72, 1953.

TRICART, Jean. La géomorphologie et la pensée marxiste. La Pensée, $n^{\circ}$ 69, pp. 55-76, 1956.

WALKER, Peter A. Political ecology: Where is the ecology? Progress in Human Geography, v. 29, nº 1, pp. 73-82, 2005.

Marcelo Lopes de Souza é Professor Titular do Departamento de Geografia da Universidade Federal do Rio de Janeiro (UFRJ) e pesquisador do CNPq. E-mail: mlopesdesouza@terra.com.br 